\title{
STRATEGI PENINGKATAN KUNJUNGAN WISATAWAN KE DANAU DENDAM TAK SUDAH KOTA BENGKULU
}

\author{
Eti Arini ${ }^{1}$, Budi Astuti ${ }^{2}$, Adi Sismanto ${ }^{3}$ \\ 1,2,3) Universitas Muhammadiyah Bengkulu
}

\begin{abstract}
The purpose of this study is to determine the marketing strategy, strengths, weaknesses, opportunities and threats to the natural tourism of Lake Dendam Tak Sudah, Bengkulu City in order to increase tourist visits. Based on the natural tourist attraction, this research was conducted in the tourist attraction of Danau Dendam Tak Sudah, Bengkulu City. The methods used in this research are interviews, documentation, and observation. Sources of data used are secondary data and primary data. The data collection technique in this study was accidental sampling with a qualitative descriptive analysis method. Then the data were analyzed using SWOT analysis to determine the factors inhibiting the lack of tourists visiting Dendan Tak Sudah Lake natural attractions in Bengkulu City. Based on the results of the study and discussion, it can be concluded that the area has enormous opportunities and strengths in the form of a very beautiful and exotic tourism potential, located in the middle of the city but with minimal facilities and infrastructure, public facilities., promotion and management roles are not maximal in structuring so that tourists who come are still very minimal.
Keywords
: Strength, Weaknesses, Opportunities, and Threats (SWOT)
Correspondence to
: etiarini@umb.ac.id

\section{ABSTRAK}

Tujuan dari penelitian ini adalah untuk mengetahui strategi pemasaran, kekuatan , kelemahan, peluang dan ancaman terhadap wisata alam Danau Dendam Tak Sudah Kota Bengkulu dalam rangka meningkatkan kunjungan wisatawan. Berdasarkan daya tarik wisata alam tersebut maka penelitian ini dilakukan di obyek wisata Danau Dendam Tak Sudah Kota Bengkulu. Metode yang digunakan dalam penelitian ini adalah wawancara, dokumentasi, dan observasi. Sumber data yang digunakan adalah data sekunder dan data primer. Teknik pengumpulan data dalam penelitian ini adalah secara accidental sampling dengan metode analisis deskriptif kualitatif, Kemudian data dianalisis dengan menggunakan analisis SWOT untuk mengetahui faktor-faktor yang menjadi penghambat kurangnya wisatawan berkunjung ke wisata alam Danau Dendan Tak Sudah di Kota Bengkulu. Berdasarkan hasil kajian dan pembahasan dapat disimpulkan bahwa daerah tersebut memiliki peluang dan kekuatan yang sangat besar berupa potensi wisata yang sangat indah dan eksotis, terletak di tengah kota namun minim sarana dan prasarana, fasilitas umum, promosi dan pernanan manajemen kurang maksimal dalam penataan sehingga wisatawan yang datang masih sangat minim.

Kata Kunci: Kekuatan, Kelemahan, Peluang, dan Ancaman (SWOT)

Riwayat Artikel:

Received : 12 November 2020

Revised : 2 Januari 2021

Accepted :11 Januari 2021 


\section{PENDAHULUAN}

Pariwisata adalah tempat kunjungan yang akan di datangi oleh para wisatawan yang ingin melakukan kunjungan ke suatu tempat untuk sementara waktu dan pada saat waktu libur, objek wisata yang ada di Bengkulu sangatlah pesat, di Bengkulu ada beberapa objek wisata alam di antaranya, Pantai Panjang, Tapak Padri Benteng Malboro,dan Danau Dendam Tak Sudah masih banyak lagi tempat wisata manarik untuk di kunjungi oleh para wisatawan dalam maupun wisatawan luar.

Untuk memikat minat para wisatawan berkunjung kedaerah Bengkulu maka para anggota dinas kebudayan dan parawisata Kota Bengkulu haruslah berkerja lebih karas lagi agar dapat memberikan kepuasan tersendiri bagi wisatawan.yang harus dilakukan adalah malakukan strategi-strategi pemasaran yang dapat memikat daya tarik para pengunjung .

Di Indonesia kaya akan objek wisata yang melimpah maka dari itu Indonesia adalah Negara yang serba multi yaitu multi insuler,multi budaya,bahasa,maupun multi agama.Maka dari itu jika kesemuanya itu di kelola dengan baik maka dapat di jadikan sebagai pontensi untuk memakmurkan rakyat dan memajukan bangsa kita. Ada banyak cara untuk memajukan pariwisata dinegara kita,memang bukan tugas para pemerintah saja yang berkewajiban untuk meningkatkan Kunjungan parawisatawan tapi juga menjadi kewajiban msyarakat juga,namun memang tentunya tugas bagi dinas pariwisata sebagai instansi pemerintalah yang lebih besar dalam bertugas untuk memajukan pariwisata yang lebih baik, yang memiliki tanggung jawab yang besar dalam pengelolaan nya.

Usaha di bidang pariwisata merupakan hal yang paling diminati oleh para pengusaha dunia, karena perannya yang sangat strategis tidak hanaya menyangkut para pengusaha tetapi bagi pemerintah dan masyarakat, pembangunan sector pariwisata juga menjadi perhatian dalam pembangunan di propinsi Bengkulu, hal ini tercermin dari kebijakan daerah untuk mengembangkan dan menggali potensi wisata yang ada di Kota Bengkulu itu sendiri seperti: Danau Dendam Tak Sudah.

Objek pariwisata yang ada di Kota Bengkulu merupakan salah satu motipasi utama para wisatawan untuk melakukan kunjungan, tetapi dengan adanya keindahan belumlah cukup untuk memikat perhatian para wisatawan karena semua itu harus juga di lengkapi dengan segala sesuatu pasilitas kelancaran transportasi, penginapan dan juga tingkah laku masyarakat sekitar.

Untuk meningkatkan dan mengembangkan pariwisata yang ada di Bengkulu agar lebih maju pemeritah daerah harus malakukan evaluasi dan strategi pemasaran objek wisata alam untuk meningkatkan kunjungan wisatawan di Bengkulu, sehingga dapat di rumuskan apa yang menjadi masalah dan hambatan di dalam perkembangan pariwisata itu sandiri ,agar lebi tepat dalam menentukan arah pemasaran dan menentukan straregi pemasaran maka pemda Kota Bengkulu harus terlebih dahulu mengevaluasi dan menganalisis objek wisata alam itu sendiri mengenai setrategi SWOT yakni: Kekuatan (strength), Kelemahan (weakness), Peluang (opporyunuty), Ancaman (treats).

Analisis SWOT adalah yang menentukan strategi pengembangan parawisata yang sangat penting dalam menentukan perkembangan pariwisata yang ada di Kota Bengkulu seperti pantai panjang,tapak padri,danau dendam tak sudah, Apabila di telaah lebih jauh mengenai Kekuatan (S),pariwisata di Kota Bengkulu memiliki keindahan alam yang mengesankan dengan pesona alam yang mempesona misalnya objek wisata danau dendam tak sudah yang memiliki keindahan cagar alamnya, perbukitan dan pepohonan yang rindang tumbuh dengan subur.

Sedangkan kelemahan (W), pariwisata di Kota Bengkulu masih belum maksimal di dalam pemeliharan dan kurang dikenalnya pariwisata yang ada di Kota Bengkulu di mata dunia, dan bila dilihat dari segi peluang $(\mathrm{O})$, pariwisata di Kota Bengkulu memiliki peluang yang cukup besar apabila pariwisata di 
mafaatkan dengan semestinya dan apabila sebaliknya dengan kurangnya perhatian dan pemeliharan yang maksimal maka akan timpulnya sebua ancaman(T).

\section{METODE PENELITIAN}

Definisi operasional untuk variable yang diteliti dapat dilihat dan di jelaskan di dalam tabel 1 .

TABEL 1: Definisi Operasional Variabel

\begin{tabular}{|c|c|c|}
\hline No & Variabel & Item Pertanyaan \\
\hline 1 & $\begin{array}{l}\text { Pariwisata } \\
\text { di Kota } \\
\text { Bengkulu }\end{array}$ & $\begin{array}{l}\text { Danau Dendam Tak Sudah } \\
\text { Merupakan kawan cagar alam } \\
\text { yang menyimpan keindahan dan } \\
\text { kekayan alam yang mempesona } \\
\text { dan menyimpan banyak pontensi } \\
\text { bagi kelestarian ekologi dan } \\
\text { keseimbangan ekosistem. }\end{array}$ \\
\hline 2 & $\begin{array}{l}\text { Analisis } \\
\text { SWOT }\end{array}$ & 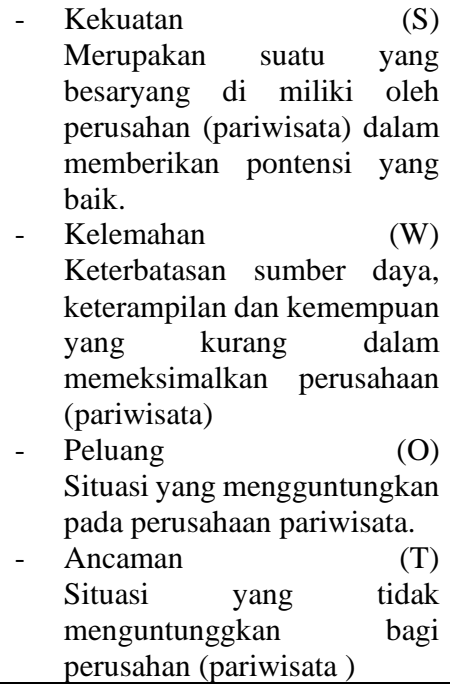 \\
\hline
\end{tabular}

Istifatul latifa (2013) Analisis strategi pemasaran dengan berdaya saing dengan menggunakn analisis SWOT (Studi Kasus Pada PT. Astra International Tbk. Honda dan Mulia Motor Cabang Argamakmur )

Penelitian ini berfungsi untuk mengetahui strategi pemasaran yang tepat dan berdaya saing dengan terlebih dahulu meng identifikasi, menilai faktor-faktor internal perusahaan dan faktor eksternal lingkungan yang mempengaruhi perusahaan tersebut.Hal ini dilakukan dengan Analisis SWOT (Stenght, Weakness, Opportunity,
Threat).Analisis SWOT adalah analisis yang digunakan untuk mengevaluasi peluang dan ancaman dilingkungan bisnis maupun kekuatan serta kelemahan yang dimiliki internal perusahaan.Penelitian ini dilakukan dengan metode survei (wawancara).

Pada General Manager dan staf pemasaran perusahaan dan konsumen perusahaan.hasilnya kemudian dianalisis dengan metode Analisis SWOT yang terdiri dari Analisis Internal IFAS dan Analisis Eksternal EFAS. Hasil penelitian menunjukkan bahwa strategi pemasaran yang dilakukan PT. Astra International Tbk. Honda adalah Strategi grow dan build, sedangkan Mulia Motor adalah Strategi Harvest atau divestiture. Perusahaan dapat menggunakan strategi perusahaan sebelumnya dengan

memperbaiki beberapa kelemahan perusahaan dan menghindari atau bertahan melawan ancaman perusahaan dengan menciptakan strategi berdaya saing. Dan posisi PT. Astra International Tbk. Honda berada dibawah Mulia motor hal ini dapat dilihat dari hasil penelitian diagram SWOT yaitu kekuatan dan kelemahan, peluang dan ancamannya.

Nur Afrillita T,(2013)Analisis SWOT dalam menentukan strategi pemasaran sepeda motor pada PT. SAMEKARINDO INDAH DI SAMARINDA, Penelitian ini bertujuan untuk mengidentifikasi dan menjelaskan kekuatan dan kelemahan (lingkungan internal) serta peluang dan ancaman (lingkungan eksternal) serta merumuskan srtategi pemasaran sepeda motor yang tepat melalui analisis SWOT (Strengths, Weaknesess, Opportunities, dan Threats) pada PT. Samekarindo Indah Samarinda. Hasil penelitian yang dilakukan penulis pada PT. Samekarindo Indah adalah dengan menggunakan alat analisis SWOT.

Pada penelitian ini yang dilakukan peneliti adalah mencari data yang sebenarnya yang akurat dan sebenarnya, menurut J'Supranto (1997:36), penelitian ini di lakukan adalah diskripsi, yaitu penelitian yang menguraikan krakteristik (sifat-sifat) tentang suatu keadan pada waktu tertentu.

Menurut Singarimbun (1999:152) populasi adalah jumlah keseluruhan dari unit analisis yang cirri-cirinya akan di duga 
populasi yang di ambil dalam penelitian ini adalah pengunjung atau wisatawan yang datang ke objek wisata Danau Dendam Tak

Sudah Kota Bengkulu, dengan menyajikan wawancara kepada responden maupun pihak yang terkait. Dengan melihat pengunjung yang berkunjung ke objek wisata Danau Dendam Tak Sudah Kota Bengkulu maka agar lebih dipermudah dalam pengambilan sempel dalam penelitian ini,peneliti hanya mewawancarai 100 responden dari jumlah wisatawan yang datang berkunjung ke objek wisata Danau Dendam Tak Sudah Kota Bengkulu, Dengan mengunakan Accidental sampling yaitu pengambilan sampel dari wisatawan mana saja yang berkunjung ke objek wisata alam Danau Dendam Tak Sudah Kota Bengkulu Krateria responden yang diambil dalam penelitian ini adalah:

1. Wisatawan yang berkunjung ke objek wisata Danau dendam tak Sudah Kota Bengkulu

2. Pihak-pihak yang terkait dengan objek wisata Danau Dendam Tak Sudah Kota Bengkulu

Pengumpulan data dalam penelitian ini dilakukan melalu 3 (tiga) cara, yaitu: Observasi (Observasi) adalah pengumpulan data dengan cara melakukan pengamatan langsung pada lokasi penelitian, dalam hal ini di Lokasi untuk melengkapi catatan penelitianyang diperlukan.)

Dokumentasi (Teknik pengumpulan data dengan cara mendapatkan data melalui literatur yang berhubungan dengan objek penelitian).

Wawancara (Merupakan pengumpulan data dengan bertanya langsung atau melalaui pihak-pihak yang berhubungan langsung dengan maslah yang akan di teliti.)

Penelitian ini menekankan pada pada pemahaman mengenai masalah- masalah dalam kehidupan sosial berdasarkan kondisi realitas atau natural setting yang holistic, komplek, dan rinci, dengan menganalisis ,kekuatan, kelemahan, peluang,dan ancaman (SWOT analisis) terhadap perkembangan pariwisata Kota Bengkulu .untuk menentukan formulasi strategi kedepan di lakukan pengabungan dari formulasi strategi yang dihubungkan dengan matrik SWOT.

Matrik internal-eksternal ini dikembangkan dari model General Elektrik (GE-Model). Parameter yang digunakan meliputi parameter kekuatan internal perusahaan dan pengaruh eksternal yang dihadapi. Tujuan penggunaan model ini adalah untuk memperoleh strategi bisnis ditingkat korporat yang lebih detail (Rangkuti, 2005:42).

Rencana pemasaran pariwisata

Tujuan, visi dan Misi pemasaran pariwisata Kota Bengkulu

Visi

Terwujudnya Kota Bengkulu sebagai Kota tujuan wisata menuju ekonomi kreatif' yang dapat di artikan sebagai ke seimbangan antara pertumbuhan, pemerataan dan kelestarian dalam pengembangan pariwisata Kota Bengkulu.

Misi

1. Menumbuhkan kesadaran baru dalam pemahaman fenomena pariwisata yang berbudaya dan berkelanjutan

2. Menumbuhkan motivasi dan komitmen segenap pelaku pariwisata Kota Bengkulu, baik masyrakat dan berkelanjutan

3. Menumbuhkan prakarsa, inisiatif, partisipasi masyrakat untuk mengembangkan dan melkukan inovasi produk berbudaya sebagai basis pembangunan, khususnya pengembangan pariwisata

4. Mendorong terciptanya iklim investasi dan bisnis pariwisata sebagai kondosif dan terencana serta terintergritas degan sector lainya

5. Mendorong kearah kebijakan dan program pembangunan khususnya pariwisata yang berbasis berbudaya dan ramah lingkungan.

Strategi Pemasaran objek wisata alam Danau Dendam Tak Sudah Kota Bengkulu

Strategi pemasaran adalah salah satu kegiatan pokok yang slalu dilakukan oleh sebuah perusahan untuk melakukan kelangsungan atas kemajuan perusahan dalam menentukan arah dan tujuan,maka perlunya di 
adakan perumusan strategi pemasaran maka strategi pemasaran merupakan rencana utama untuk mencapai sebuah tujuan setelah dilakukan tujuan, maka tujuan perumusan dan strategi yang di sebut taktik, di dalam strategi harus memiliki langkah yang dapat membangun agar dapat memberikan kemajuan yang pesat yang akan datang dalam rangka memperkuat atau memperbarui strategi yang akan datang.

Untuk mengetahui kondisi tersebut maka dapat di lakukan dengan cara menganalisis SWOT yaitu dengan mengetahui apa saja kekuatan, kelemahan dan peluang, analisis ini di perlukan untuk mengetahui apa yang menjadi kekuatan dan kelemahan yang menjadi faktor eksternal, peluang dan ancaman yang menjadi factor internal yang mempengaruhi pemasaran.

\section{HASIL PENELITIAN}

\section{Kunjungan wisatawan Kota Bengkulu}

Dari hasil penelitian yang telah dilaksanakan di objek pariwisata Kota Bengkulu dengan menggunakan observasi, wawancara, maupun dokumentasi, karena dapat di ketahui bahwa kunjungan wisatawan Kota Bengkulu baik domestic maupun mancanegara dari tahun 2013 sampai 2017 mengalami kenaikan seperti di ketahui untuk tahun sebelumnya pengunjung yang datang ke kawasan ini padahal kawasan ini memiliki potensi alamyang sangat menakjukan. Maka dari itu Pemprov Bengkulu memprogramkan pariwisata melalui upaya-upaya yang besar untuk meningkat kan kunjungan wisatawan antara lain dengan memperbaiki secara berlahan untuk memperbaiki intrukstur bangunan objek wisata dan sarana penujang yang lain,serta meningkatkan promosi yang sangat besar-besaran untuk memperkenalkan objek wisata tersebut,dari tahun sebelumnya sampai sekarang menumbuhkan hasil yang positif bagi masyrakat dengan meningkatnya jumlah kunjungan wisatawan beberapa tahun terakhir.
TABEL 2: Perkembangan Kunjungan Wisatawan Tahun 2013-2017

\begin{tabular}{ccc}
\hline Tahun & $\begin{array}{c}\text { Jumlah } \\
\text { Wisatawan }\end{array}$ & Pertumbuhan (\%) \\
\hline 2013 & 45546 & - \\
\hline 2014 & 63608 & 4 \\
\hline 2015 & 75010 & 0 \\
\hline 2016 & 72233 & 1 \\
\hline 2017 & 90550 & 9 \\
\hline
\end{tabular}

Sumber: Penelitian 2018

Dilihat dari table di atas dari tahun 2013 sampai 2017 pengunjung mengalami peningkatan di setiap tahun ketahun ,hal ini karena ada usaha dari pemerintah yang telah melakukan usaha yang sangat keras untuk mempermosikan objek wisata alam Kota Bengkulu seperti menggelar event- event yang dapat mengundang wisatawan dari dalam maupun dari luar, seperti acara tabot, acara tarian adat tradisional, dan berbagai lainnya di berbagai daerah dengan tujuan untuk memperkenalkan objek wisata, dengan cara menyediakan buku panduan tentang pariwisata, dan melakukan promosi lewat situs internet, koran, dan terjun secara langsung kedaerah-daerah dengan cara memberikan brosur tentang pariwisata yang ada diKota Bengkulu.

\section{PEMBAHASAN}

Panorama pemandangan di kawasan objek wisata Danau Dendam Tak sudah sejau mana mata memendang pemandangan yang indah, bukit-bukit yang kebiruan terhat sayupsayup terlihat kejauhan sejauh mana mata memandang memenjakan pengunjung yang datang ke objek wisata alam Danau ini dan tidak luput juga di sekitar Danau ini menjadi kawasan cagar alam kerena adanya tanaman langka yang akademik yang hanya tumbuh di kawasan Danau ini saja yaitu Angrek Pensil (Vanda Hokareana) dan beberapa flora lainnya seperti, angrek matahari, Sekenduduk, Pulai, Ambacang Rawa, Bakung, Nipah, Terentang, Brosong dan Fakis dan di Danai ini juga hidup beberapa fauna yang di lindungi seperti, kera 
ekor panjang, lutung, burung kutilang, babi hutan, siput dan juga berbagai ikan langka seperti kabakung dan Palau.

Kekuatan (S) di Danau Dendam Tak Sudah ini kita dapat menyaksikan panorama pemandangan alam yang berupa permukan Danau yang dapat berubah-ubah pada saat sang surya akan terbenam dan terbit yang terlihat dari kejauhan yang sangat ideal untuk di abadikan oleh lensa kamera. Danau ini memiliki bentangan seluas 37 hetar, berair tenang dan jerni. Lokasi Danau ini berada di kecamatan Teluk Segara,jarak tempuh sekitar $7 \mathrm{~km}$ dari pusat Kota Bengkulu, akses untuk menuju lokasi ini menggunakan dengan jalur darat yang dapat digunakan dengan kendaraan pribadi dan juga bus pariwisata yang dapat di gunakan untuk dapat berkunjung ke lokasi.

Disekitar kawasan Danau Dendam Tak Sudah masyarakat /warga telah menyediakan pondok yang menawarkan berbagai jenis makanan dan minuman yang dapat langsung di nikmati sambil sambil melihat suasana yang dapat memanjakan mata para pengunjung.

Kelemahan (W). dengan lokasi pemandangan Danau Dendam Tak Sudah yang indah ,jangan sampai membuat wisatawan yang berkunjung menjadi berkurang karena keadaan lokasi yang kurang memadai hal ini dikarenakan tempat yang kurang bersih, jalan yang rusak,kurang nya fasilitas yang seperti lampu penerangan baik dipinggir jalan maupun di sekitar danau,dan kurangnya keamanan di tempat ini menggakibatkan rawannya daerah kawasan Danau, di tambah lagi masalah tempat parkir yang kurang terkelola secara teratur, pengelolaan tempat parkir yang kurang maksimal di mamfaatkan oleh sebagian orang yang tidak bertanggung jawab, tidak tersediahnya tempat penginapan seperti, hotel, tidak adnya musolah, tidak adanya MCK umum yang mudah dijangkau untuk di mamfaatkan oleh para wisatawan yang datang untuk berunjung dan tempat bermain anakanak dan lain-lain

Peluang $(\mathrm{O})$, dilihat dari lokasi yang memiliki daya tarik yang indah membuat membuat wisatawan yang berkunjung lebih banyak, yaitu dengan membuat menyediakan lokasi penginapan, menyediakan perahu yang dapat di kayu berdua atau lebih maupun sendiri,dan menyediakan angsa-angsaan yang sebagaimana tersedia di tapak padre dengan ini di yakini menamba daya tarik para wisatawan untuk berkunjung ke kawasan Danau Dendam Tak Sudah.

Ancaman (T), perambahan cagar alam yang selalu meluas telah mengancam kondisi fisik kawasan serta sejumlah flora dan fauna yang kini mulai sulit di temui. seperti, Angrek Pensil yang merupakan flora academic unggulan Danau Dendam Tak Sudah masih yang kini berlahan mulai puna, Anggrek dengan bunga putih dipadu dengan warna ungu bintik-bintik hitam yang menjadi ciri has kawasan ini dan selalu menjadi daya tarik wisatawan untuk berkunjung ke kawasan itu, lutung dan kera ekor panjang pun kini mulai sulit untuk di temui walaupun terkadang sekali- kali masih dapat terlihat bergelantungan dipohon-pohon di kawasan Danau.

TABEL 3: Hasil Analisis SWOT Objek Wisata Danau Dendam Tak Sudah

\begin{tabular}{|c|c|c|c|}
\hline KONDISI INTERNAL & $+/-$ & KONDISI EKSTERNAL & $+/-$ \\
\hline $\begin{array}{l}\text { URAIAN KEKUATAN (S) +l } \\
\text { KELEMAHAN (W) - }\end{array}$ & & $\begin{array}{l}\text { URAIAN PELUANG }(\mathbf{O})+/ \\
\text { ANCAMAN (T) }\end{array}$ & \\
\hline 1. Pemandangan alam yang asri & + & $\begin{array}{l}\text { 1.Sumber daya pengelolaan yang kurang } \\
\text { memadai baik dari segi jumlah maupun } \\
\text { kualitas }\end{array}$ & - \\
\hline $\begin{array}{l}\text { 2. Lingkungan yang merupakan } \\
\text { daerah cagar alam }\end{array}$ & + & 2. Faselitas objek wisata yang memadai & + \\
\hline $\begin{array}{l}\text { 3. Lokasi objek wisata yang } \\
\text { merupakan tempat pendidikan dan } \\
\text { penelitian }\end{array}$ & + & 3. Potensi wisata yang memadai & + \\
\hline
\end{tabular}




\begin{tabular}{|c|c|c|c|}
\hline $\begin{array}{l}\text { 4. Jarak objek wisata yang dekat } \\
\text { dengan pusat Kota }\end{array}$ & + & 4. Jarak tempu yang sangat dekat & - \\
\hline 5. Jalan yang suda di aspal & + & $\begin{array}{l}\text { 5. Potensi objek wisata dan daya tarik } \\
\text { wisata yang belum di kelolah dan di tata } \\
\text { secara maksimal }\end{array}$ & - \\
\hline 6. Menyadiakan tempat istirahat & + & 6. Keterbatasan dana & - \\
\hline $\begin{array}{l}\text { 7. Keamanan lingkungan yang } \\
\text { masih kurang }\end{array}$ & - & $\begin{array}{l}\text { 7. Belum optimal partisifasi masiarakat } \\
\text { dalam mengambangkan pariwisata }\end{array}$ & - \\
\hline $\begin{array}{l}\text { 8. Minimnya lampu penerangan } \\
\text { jalan maupun sekitar danau } \\
\text { masyrakat disekitar kawasan yang } \\
\text { kurang ramah }\end{array}$ & - & $\begin{array}{l}\text { 8. Penambangan elegal yang merusak } \\
\text { lingkungan }\end{array}$ & - \\
\hline 9. Banyak nya jalan yang rusak & - & 9. Keamanan lingkungan yang kurang & - \\
\hline $\begin{array}{l}\text { 10. Tempat parkir yang belum } \\
\text { teratur }\end{array}$ & - & & \\
\hline 11. Kurang nya sarana hiburan & - & & \\
\hline $\begin{array}{l}\text { 12. Kurngnya faselitas sarana dan } \\
\text { prasaran seperti mosolah, mck } \\
\text {,tempat bermain anakanak dan } \\
\text { sebagainya }\end{array}$ & - & & \\
\hline Jumlah $(+)=6(-)=6$ & 0 & Jumlah $(+)=3(-)=6$ & (-) 3 \\
\hline
\end{tabular}

Sumber: data dikelolah 2018

Untuk melakukan analisis SWOT terlebih dahulu digunakan diagram analisis SWOT untuk mengetahui posisi perkembangan objek wisata Danau Dendam Tak Sudah, seperti di bawah ini:

\section{Gambar 1: Matrik SWOT}

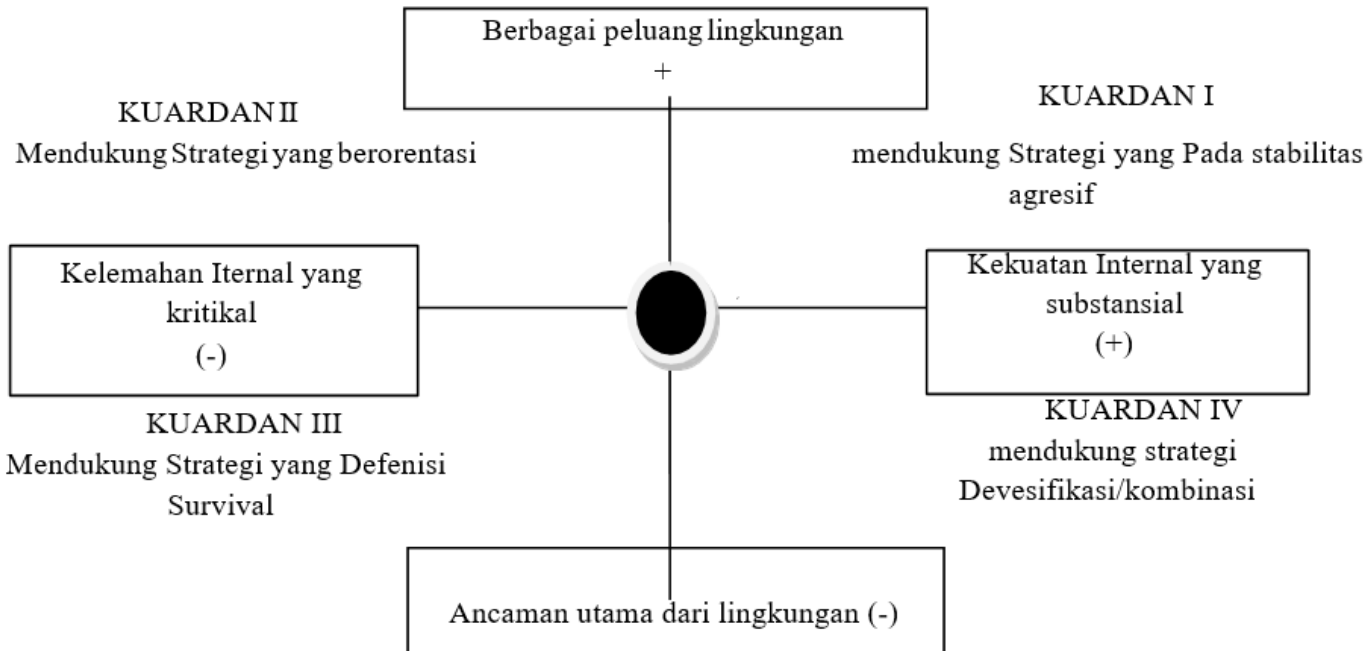

Sumber: data dikelolah 2018

Dari hasil analisis SWOT yang telah di kerjakan pada objek pariwisata Danau Dendam Tak Sudah terhadap potensi yang ada pada saat ini di ketahui bahwa strategi pemasaran yang telah di lakukan, di lihat dari kondisi internal dan eksternal objek wisata Danau Dendam Tak Sudah berada pada pada perkembangan yaitu Kuardan I yang masih menuju kearah ekspansasi. Hal inidi sebabkan 
karena masih belum nya di mamfaatkan peluang yang ada di kawasan Danau Dendam Tak Sudah serta kekuatan nya pun belum berjalan secara maksimal. Peluang-peluang tersebut sumber daya dan pengalokasian dana yang belum jelas arahnya hal ini terlihat dari tahun ketahun tidak adanya peningkatan baik sarana maupun prasarana penujang objek pariwisata Danau Dendam Tak Sudah, ditamba lagi dengan masiyarakat sekitar yang kurang ramah, hal ini di buktikan oleh responden yang di wawancari yang di jadikan responden penelitian, bahwah masyrakat yang memberikan harga yang melampaui batas terhadap suatu produk atau makanan yang di perjualbelikan, hal ini mengakibatkan wisatawan tidak akan berminat untuk datang kembali ke kawasan ini, maka hal inilah yang harus di benahi karena hal ini lah yang menyebabkan kurang kunjungan wisatawan ke kawasan Danau Dendam Tak Sudah. Terjadinya hal tersebut karena tempat istirahat/ persinggahan adalah buatan dari pemilik warung yang memiliki lokasi masingmasing sehingga harga produk atau makanan nya pun berpariasi, jadi fanomena semacam ini harusnya cepat ada antisifasi dari pemerintah dengan membangun tempat istirahat yang geratis atau tidak di pungut biaya bayaran yang berlebihan, sehingga wisatan akan lebih nyaman berkunjung ke kawasan Objek wisata Danau Dendam Tak Sudah.

\section{KESIMPULAN}

Wisata Kota Bengkulu terutama kawasan Danau Dendam Tak Sudah. Dengan keanekaragaman budaya dan kesenian di percaya dapat memberikan keputusan yang besar bagi minat para wisatawan untuk berkunjung ke kawasan wisata ke suatu daerah,selain potensi alam yang memedai tetapi tentunya keberadaan infrastruktur aksessibilitas udara,laut, dan darat dan tentunya kualitas layanan dan pelayanan juga menjadi penunjang utama untuk menarik minat wisatawan untuk berkunjung ke kawasan wisata alam.

Untuk mendukung pemasaran pariwisata, suatu objek wisata haruslah mempunyai nilai yang strategis, ekonomis, sosial, dan politik serta keamanan pengunjung karena pengunjung atau wisatawan merupakan sumber pemasukan bagi perusahaan pariwisata untuk itu ada beberapa hal yang harus di lakukan oleh dinas pariwisata seperti:

1. Mendorong wisatawan mengunakan jasa dan produk yang di produksi guna meningkatkan produktivitas pemerintah dengan meningkatkan fasilitas yang memadai.

2. Pemerintah dapat menarik pengunjung dengan jangkauan yang lebih luas dengan meningkatkan strategi promosi dengan menggunakan media-media yang dekat dengan konsumen

3. Pemerintah dapat memilih segmentasi baru untuk memperluas jangkauan pemasaran dengan menamba fasilitas.

\section{DAFTAR PUSTAKA}

Alfandi.2001. Ilmu Pariwisata Sebuah Pengantar Perdana. Jakarta: Pradnya Paramitha.

Alma. Buchari, 2004. Manajemen Pemasaran dan Pemasaran Jasa. Bandung: Alfabeta. Bandung

Basu Swasta dan Irawan. 2008. Strategi Pemasaran, Penerbit Andi, Yogyakarta.

Freddy Rangkuti. 2005. Analisis SWOT: Teknik Membedah Kasus Bisnis. Jakarta: PT. Gramedia

Kotler P, 2005. Manajemen Pemasaran: Analisis, Perencanaan, Implementasi dan Kontrol, Alih bahasa oleh Hendra Teguh, SE dan Ronny A Rusli,Se,Ak. Jilid 1, Jakarta, PT Prenhallindo.

Latifa, Istifatul 2013, Analisis starategi pemasaran berdaya saing dengan menggunakan analisis SWOT, skripsi 
BALANCE: Economic, Business, Management, and Accounting Journal

manajemen Pemasaran universitas Muhamadiyah Bengkulu.

Spillane J.J,1987,Pariwisata Indonesia SejarahdanProspeknya, Yogyakarta, Kanisius, 150 halaman

Sugiyono.2010. Metode Penelitian Kuantitatif dan Kualitatif. Yogyakarta: BPFE. 